J. Dairy Sci. 101:5668-5668

https://doi.org/10.3168/jds.2018-101-6-5668

(c) American Dairy Science Association ${ }^{\circledR}, 2018$.

\title{
Corrigendum to "Characterization of the chemical structures and physical properties of exopolysaccharides produced by various Streptococcus thermophilus strains" (J. Dairy Sci. 100:3424-3435)
}

\section{U. Pachekrepapol, J. A. Lucey, Y. Gong, R. Naran, and P. Azadi}

In Figure 2, on page 3431, the structures of some of the exopolysaccharide repeating units were incorrect. The corrected figure is shown below with revised structures for ST-10255y and ST4239, St-143, and STCth-9204 (Figure 2, parts d, e, and f)

The authors regret the errors.

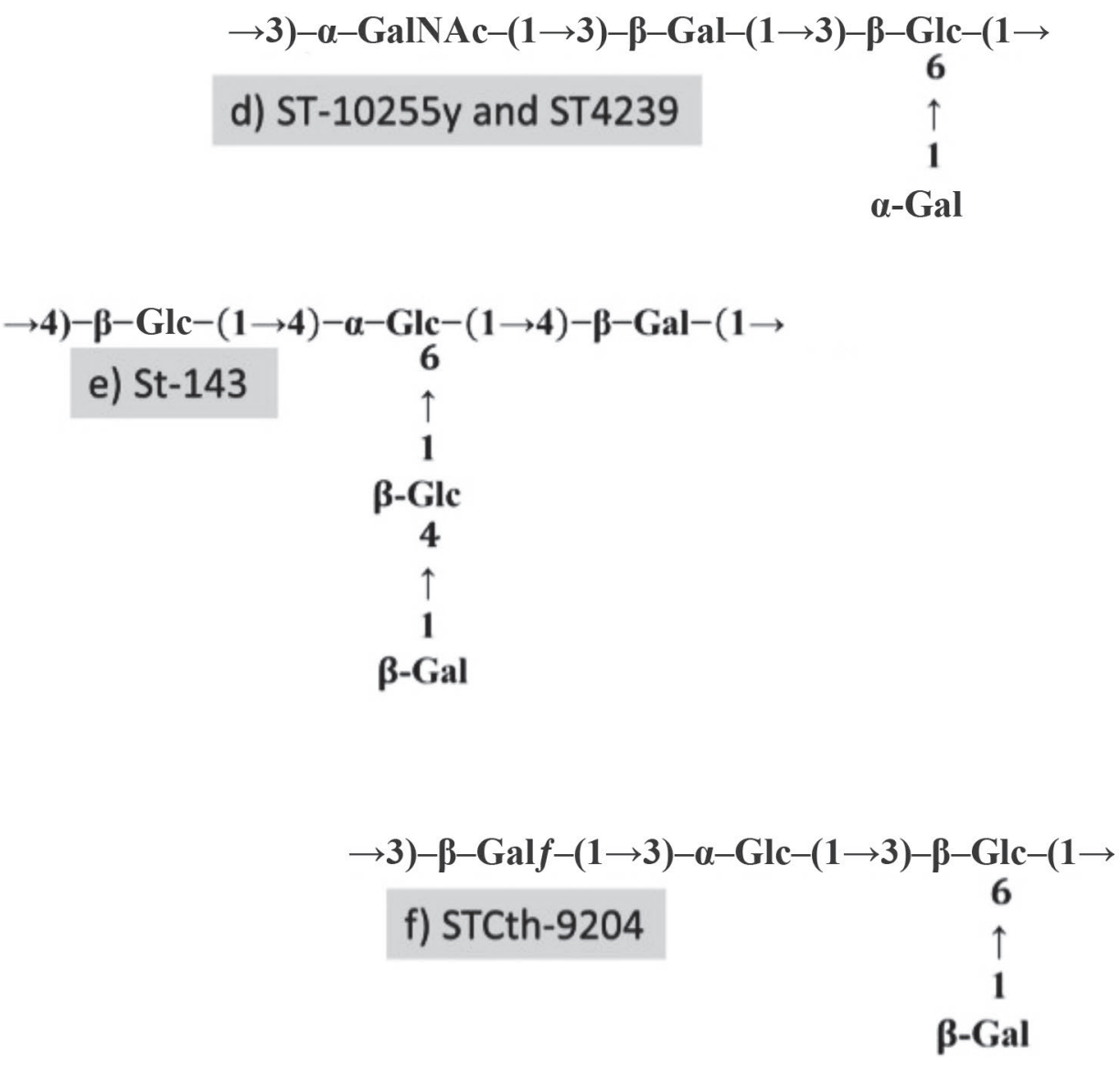

Figure 2. Structure of repeating units of exopolysaccharide (EPS) isolated from different Streptococcus thermophilus strains: (a) DGCC 7698, (b) DGCC 7710, (c) DGCC 7785, (d) ST-10255y and ST4239 (they had same repeating unit structure), (e) St-143, and (f) STCth-9204. The structures for (a), (b), and (c) were provided by DuPont (Madison, WI), whereas EPS structures for strains (d), (e), and (f) were experimentally analyzed in collaboration with the Complex Carbohydrate Research Center, University of Georgia (Athens, GA).

\section{REFERENCES}

Pachekrepapol, U., J. A. Lucey, Y. Gong, R. Naran, and P. Azadi. 2017. Characterization of the chemical structures and physical properties of exopolysaccharides produced by various Streptococcus thermophilus strains. J. Dairy Sci. 100(5):3424-3435. https://doi.org/10.3168/jds .2016-12125. 